\title{
An intuitive approach to learning delivery in Higher Education
}

DOI 10.1515/ijtr-2016-0008

received September 2016; accepted November 2016

Abstract: Preparing and teaching subjects in the Higher Education environment has been attracting much attention over the past decade as the sector diversifies and adds online instruction to its on campus delivery to cater to the increased demand for flexibility and choice from students. University lecturers are now required to assume greater responsibility to develop the subject content and teaching structure for their subjects and it is the latter where lecturers don't necessarily have formal qualifications or experience. This paper describes the implementation of the Confluence of Learning framework at one university together with a style guide and a mobile app. The subsequent trial with 20 participants illustrated that a framework developed in the lecturers own context can generate a change in practice. The lecturers' comments were thematically analysed and demonstrated that an unambiguous but well structured framework will motivate and empower lecturers with their subject design resulting in a positive impact on students studying their subjects.

Keywords: Learning framework; Mobile application

\section{Introduction}

The adoption of technologies to change, enhance or improve living and working functionality is a global reality where a measurement of success or development is to gauge the adoption of a range of technologies or particular technology practices. Such is the barometric effect of technology on success, working impact and lifestyle that it could be argued there is an obsessive focus on seeking a particular technology solution in the first instance and

*Corresponding author: David Smith, Courses Director, Faculty of Arts and Education, Charles Sturt University, Australia. Email: davismith@csu.edu.au retro fitting aspects of human management, organisation and integration. The impact of technology on the higher education sector in its core foundation of teaching has a similar scenario. There have been many iterations of the teaching process since the inception of technology with administrators seeking to harness the flexibility and appeal of technology to attract a greater number of students in the global education market (Conole, 2010). At the beginning university strategies tended to concentrate on cost effective methods and in the online environment there was little thought to student engagement and other elements that made learning effective.

Current classifications of students learning experience in higher education ranges from in-class, online, and blended and still tend to be associated with how the teaching is delivered rather than how the student will be engaged with the learning process. There are a plethora of practices and philosophies that influence the way in which universities develop and deliver their academic programs to capture the promise of market trends and student demands and lifestyle. The essential conduit in the process between development and delivery is the lecturer who is knowledgeable in the nature of the subject but not necessarily in the subject delivery mode to the student.

The delivery modes of subjects in degrees or the entire degree facilitated by universities are either on or off campus and utilise a range of technologies to facilitate the exchange of information and assessment. There has been an increasing emphasis on the technologies used when teaching subjects, concentrating on the learning management system, interactive games based technologies and the use of Massive Open Online Courses. The focus on the technology associated with the subject/degree moves the attention away from how the subject is taught, the pedagogy used to engage the student with the learning material. It can further obscure the objectives of university lecturers and educational designers charged with the responsibility of developing and teaching the subject. The different demands by university administrations, employment destinations as well as by the student client base has 
confused the intention of those intending to concentrate on the primacy of learning.

\section{Learning approaches}

In the past decade there has been a distinct push by universities to re-invigorate the quality of the learning and teaching by concentrating on the pedagogical theory that drives the development and teaching of subjects within individual programs. There has been a realisation that higher education teaching was knowledge centred (Boyer, 1990) and university teaching, function and resource all revolved around this central theme. The shift to a student centred focus has provided universities with a momentum to redesign a more effective learning space that engages students (Altbach, Reisberg \& Rumbley, 2009). Universities have instituted programs designed to assist, empower and skill lecturers in design and teaching practices with the prime intention of improving the student learning experience.

Initially part of the approach called 'e-Learning', several university academics developed learning frameworks that combined a learning approach with suggested technology development. Some of the most notable frameworks were the Five Stage model by Gilly Salmon and the Conversational Model by Diana Laurillard. Salmon whilst working at the Open University (UK) developed an approach called the Five Stage Model to Online Learning (Salmon, 2000). This model combined technology skills with learning development and learning interaction and the lecturer was cast in the role of a learning moderator. The pivotal point of this model was that it mirrored the progression in quality and engagement for the student with learning material with peers and with the lecturer. Laurillard (2002) described her model as an interaction between learners and teacher using various types of mediums. Seale and Cooper further maintain that with Laurillard's model the learning process is only effective when it is based on a tutoring system (Seale \& Cooper, 2010, p. 114)). However, the interpretation required to effectively engage both models does mitigate the potential effectiveness and calls for an approach that is more grass roots and more flexible in its adoption.

\section{Confluence of learning strategy}

The initial motivation to develop the Confluence of Learning (COL) framework was to provide lecturers with an easily accessible structure for use in developing their sessional subject material for particular learning purposes. In the following paragraphs the COL framework is described together with its application as a learning strategy.

The development and utilisation of the COL framework is based on a hybrid learning theory founded on behavioural and constructivist principles where the overall approach is defined as behavioural but each element of the framework is constructivist. The framework comprises many external elements that will be utilised as stimuli to engage in a learning process that is customised for a specific individual or collective purpose.

The COL model has six major elements that provoke exploration, investigation, production and cognition. A short description of each element is listed in Table 1 below. With each description to enhance the learning design concept a set of curriculum development questions related to each has been attached along with a sample of suggested technologies that may engage or enhance the proposed learning is added to each section.

Pedagogical practices, the prescribed curriculum, assessment and the learning environment are the key elements for learning design. It is necessary to align these elements with a learning paradigm in order to optimise student learning opportunities. Ellis and Goodyear (2010) found that enhancing student learning depends upon the link between the student's experience of learning and the student's learning environment. By linking the student learning experience to their learning environment there is a conscious effort to move away from the delivery analogy of education to that of a collaboration or partnership in the development of knowledge (De Freitas \& Conole, 2010). The notion here is when knowledge is co-developed a mutually beneficial collaboration is formed where all participants are recognised as stakeholders in changing, adapting and developing curriculum.

In conjunction with the framework an assistive style guide has been developed to furnish lecturers and designers with a scaffold for the design of subjects and enable a consistent approach for subjects that are offered at the university. The style guide is a learning grid where icons have been assigned to particular pedagogical practices. Having the framework and style guide for the development and teaching of online subjects develops confidence amongst university teachers and encourages them to use the most appropriate pedagogy in their teaching. 
Table 1: The major elements of the COL model

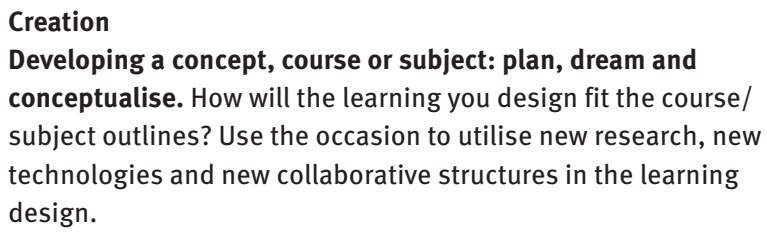

\section{Exchange}

Communicating information and dialogue between lecturer and student, student and student, student and expert mentor. What are the most appropriate modes of exchange to achieve particular learning outcomes? The use of Wikis, apps, and augmented reality to facilitate interaction and the use of bookmarking and repositories to identify and store knowledge.

\section{Assessment}

Providing the opportunity for learners to demonstrate the development of their knowledge through a variety of modes. What judgements can be made about the volume, nature and quality of learning? Can assessment be negotiated with students? In what modes can it be developed, is it flexible?

\section{Information}

Considering the information that needs to be disseminated and the most appropriate format. What information will be relevant, current, challenging, serve as stimuli, will it be synchronous or asynchronous? The use of video lecture, Skype/connect, vodcasts/ podcasts and other media repositories can orchestrate this exchange.

\section{Reflection}

Encouraging learners to evaluate and challenge their learning through exchange with their peers and with other members of the educational community. What useful knowledge has been acquired in this interaction? How can it be transformed for use in other situations? The use of blogs, forums and e-portfolios allow for students to develop their thinking.

\section{Professionalism}

Encouraging learners to develop further in their professional practice and standing and know that what they do and develop meets professional standards. Has the student developed a stronger connection with their professional learning community? Active connections to professional learning community websites and academic social media facilitate some of this development.
This approach also ensures a collaborative and consistent online learning development within the faculty or school giving students a consistent learning signpost for the type of learning they need to prepare for and show evidence for. Lecturers evaluate the material to be taught, reflect on the learning for each section and highlight the focus by using the style guide which is then broadcast to the students by means of the relevant icon.

The four elements of the COL framework that focus on teaching are information, exchange, reflection and assessment with creation and professionalism focusing more on conceptual design and contributions to appropriate communities of practice. The style guide utilises the four identified elements of the COL framework to provide a multi-strand conduit for lecturers between theory of learning and the practice of teaching. The structure of the style guide displays the four teaching elements (see Table 2) and the various components of each element cross referenced with teaching functions that may be used across a range of learning environments. The framework describes how learning functions could be used across each of the four elements; for example, if the lecturer wanted to use journaling to develop thinking then journaling could be used to initiate inquiry, develop thinking or use professional practice skills to exchange information on the learning focus.

To further embed the link between technology and pedagogy a mobile application was developed to provide lecturers with technology suggestions for particular learning purposes. Having suggestions readily available in a recognisable context for lecturers builds on the lecturer's pivotal role as guiding the learning interaction with students to facilitate effective learning and knowledge creation (Marks, Sibley \& Arbaugh, 2005) as well as enhancing lecturer confidence in pedagogical design. The application called Technology for Online Interactive Learning (TfOIL) is structured according to the four COL elements that focus on teaching. TfOIL was first made available in August 2015 in a closed platform at one Australian university and then the interface was redesigned in March 2016 and was open. TfOIL has three operational layers with the functions of layers two and three described in Table 3.

Navigating to the last screen (Figure 1) is dependent on choices in layers 2 and 3. In the particular example shown 'Information' was selected in layer 2 and 'Presenting the Information' in layer 3.

Using the COL framework with its supportive structures has become a research focus to evaluate and assess impact upon teaching practices within a university setting. To capture the conversations of lecturers as they used the TfOIL app and style guide to prepare and teach their subjects an instrumental case study approach was selected. Instrumental case studies allow the researcher to gather data using a perspective from someone within the organization (Stake, 1995). The conversations are analysed according to Braun and Clarke's (2006) thematic analysis as it allows for minimal organization as well as describing the data set in rich detail.

I conducted a pilot study in 2013 (Smith, 2016, p. 7) to determine the mobile application's suitability and 
Table 2: Style Guide used for developing subjects

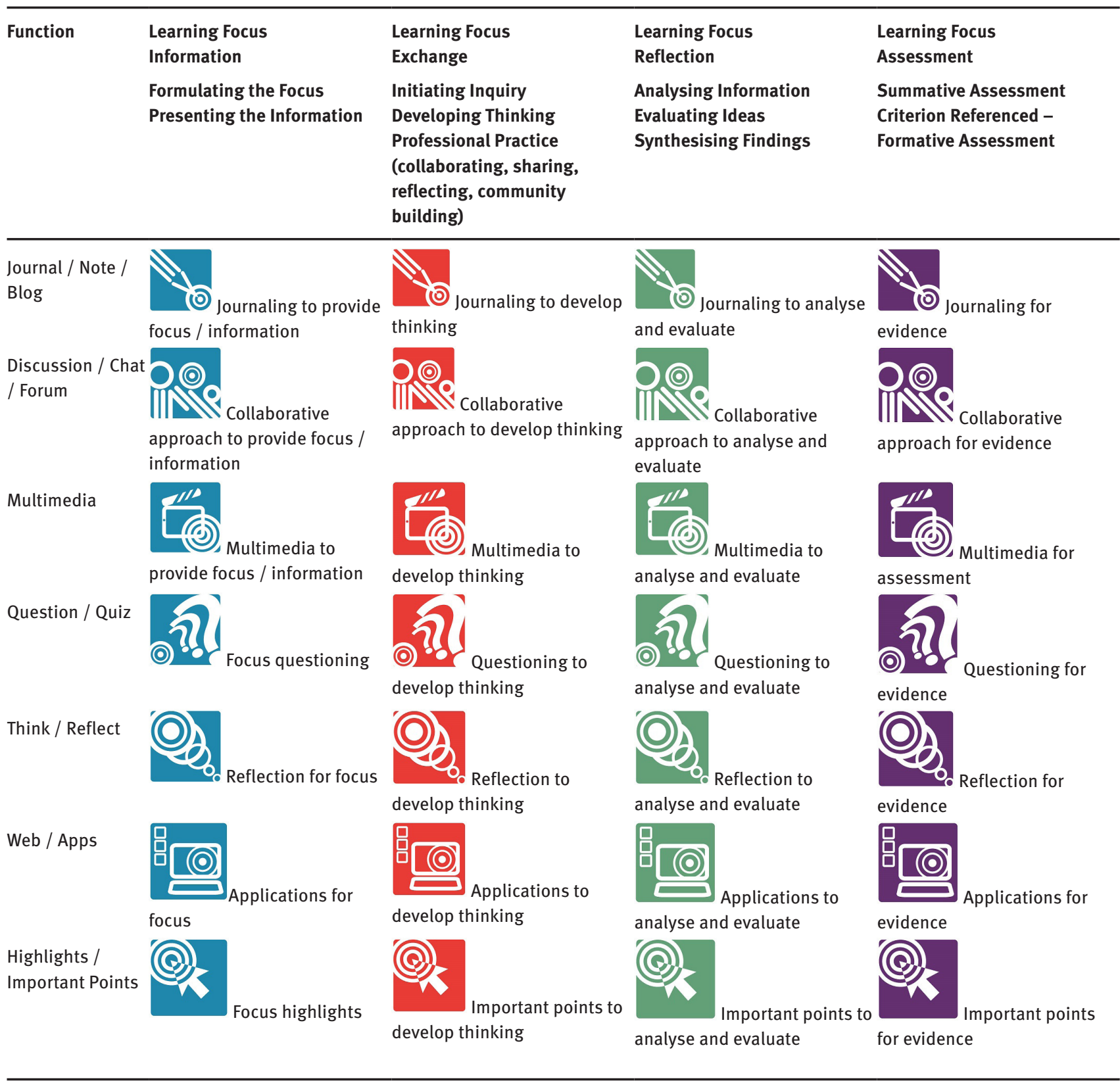

usability with the style guide. The study found that the lecturers who participated adopted a positive attitude to the use of the app and style guide and this attitude persisted throughout the course of the pilot. Issues identified were time taken to open software applications for the first time and opening the TfOIL app on tablet and other smart devices and as a result coding modifications to the app will occur for the next iteration of TfOIL. Lecturers commented positively about the style guide, its pedagogical appropriateness and the ease in which students associated the style guide with the intended learning.

\section{Framework study}

In June 2016 a study involving 20 lecturers in one regional Australian University commenced for a one month period. The study involved an individual briefing session and then concluded with an observation session at the end of one month. The briefing session included an explanation of the COL framework and its connection to the style guide and TfOIL application. Applying the style guide and use of TfOIL was also explained. Each participant practiced using the style guide as well as using TfOIL on their computer, tablet and smart phone. Lecturers were then asked 
Table 3: Description of Layer 2 and 3 of the TfOIL application

\begin{tabular}{lll}
\hline Second Layer: Lecturers would first select one element & $\begin{array}{l}\text { Third Layer: Lecturers would then select one of the three options } \\
\text { for each element }\end{array}$ \\
\hline $\begin{array}{l}\text { Information: Evaluating the information for dissemination. What } \\
\text { information will be relevant, current, challenging and serve as }\end{array}$ & $\bullet$ & Formulating the focus \\
stimuli; how will it be developed; and will it be synchronous or & $\bullet$ & Presenting the information \\
asynchronous? The use of video lecture, Skype, vodcasts/podcasts \\
and other media repositories can orchestrate this dissemination \\
process.
\end{tabular}

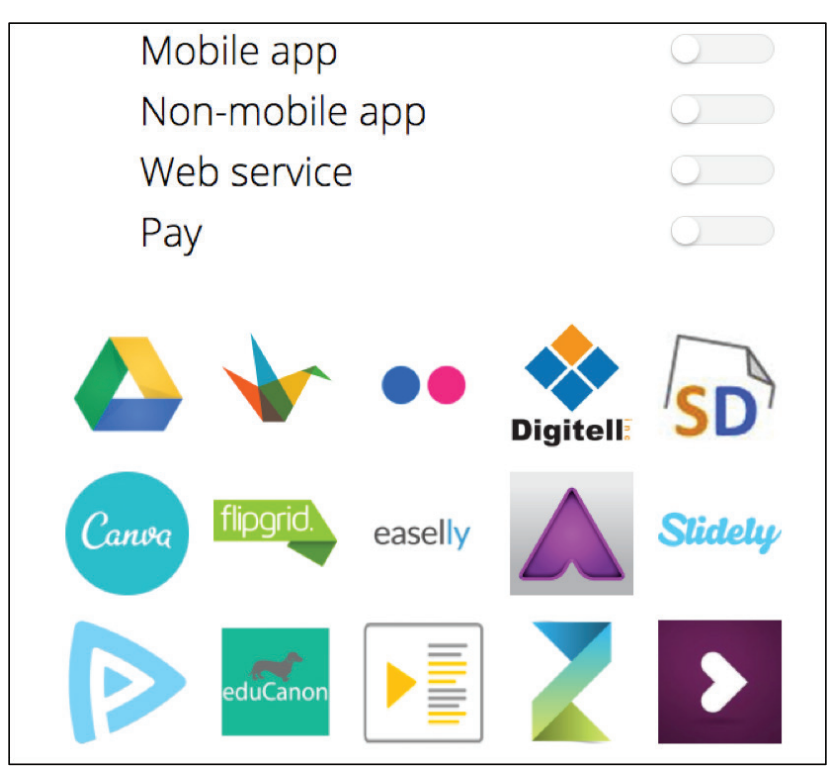

Figure 1: Final screen of TfOIL showing suggested technologies.

to develop their subject using the framework, guide and app in a one month period. In that month the lecturers could contact the researcher for any assistance or clarification needed when using the assistive design elements. There were some questions about the icon coding from the style guide particularly around the interpretation of purpose. Those who asked the question were satisfied that the interpretation was flexible and dependent upon purpose of use. At the conclusion of the month the lecturers met with the researcher individually.
At the final meeting the lecturers were asked by a series of questions to evaluate their experience of designing the teaching strategies of their subjects using the framework, the style guide and the app. The first question focused on the physical appearance of the style guide and the app. Lecturers commented on the appropriateness of using themed icons and those that had seen the first iteration of TfOIL were pleased with the improvement of the app. Lecturers were then asked about the ease of using the assistive strategies in designing the teaching strategies for their subjects. All lecturers commented on the relevance of the four student facing elements of the COL framework and after some initial apprehension in using the style guide found it easy to use and formative as it assisted lecturers in planning their work. The style guide also gave a quick visual summary and ensured that there was a variety of learning elements contained in the subject as well as being a signpost to students about the type of learning and expectations contained in each section of the module. The initial uptake of TfOIL varied as some lecturers were reluctant to move away from tried and tested technologies. However, whether it was curiosity, success with the style guide or previous use of TfOIL, lecturers all reported looking for alternatives and there was an uptake of at least two new technologies from all participants. The last question focused on using the framework again with future sessions. All lecturers were motivated to use the framework again. Whilst acknowledging that some extra time was needed to learn the nuances of the framework they did not foresee this as a future impediment. They 
Table 4: Thematic comments for Functionality

\begin{tabular}{ll}
\hline & Positive \\
\hline Connected & 86 comments \\
& Simplicity \\
& Clean design \\
& Logical connection \\
& Structural Clarity \\
& 92 comments \\
Purpose & Clear alignment to teaching \\
& Logical connection with category theme \\
& Scroll info concise \\
& 73 Comments \\
Ease & Need no prior knowledge \\
& quick \\
\hline
\end{tabular}

also liked the simplistic structure of the framework as it used an organisational language the lecturers were familiar with, which recognises the complex and less visible internal space of lecturer beliefs must be understood in relation to lecturers' pedagogical contexts and the affordances they can identify (Steel \& Levy, 2009).

The analysis of comments from the final meetings held one month after the initial meeting with the same 20 lecturers identified two major themes, functionality and learning design. Functionality was further divided into three sub-themes(Table 4); connected, purpose and ease.

Learning design was further divided into five subthemes; cross discipline, subject appropriate, technology appropriate, user value and pedagogical. In total there were 416 comments with lecturers perceiving that the framework had portability across all the faculties in the university, it was appropriate for all subject design and its structure was user designed. There was also strong acknowledgement of the viable connection between technology and pedagogy and how it facilitated, invited its use in the design of subjects. From the data the framework appears to have transformed the approach these lecturers took when they designed their subject for teaching.

\section{Summative discussion}

There is an increased focus on the range and quality of learning practices offered by higher education institutions. Lecturers now assume a greater responsibility for how their subject is taught with it be on campus or on line. Whilst lecturers are recognized experts in their chosen field, they may not be as deft when negotiating the appropriate pedagogy or technology to increase student engagement, interest and motivation. There is a need to recognize individual knowledge expertise whilst at the same time empowering lecturers to build their learning platforms.

The COL framework, style guide and app is a solution that has been trialed with some success in that it proved to be a positive catalyst in changing the subject design process. Lecturers found an empathy with the language used and the learning structure to the degree that they were motivated to try and implement the concept. The motivation experienced by lecturers developed into a momentum of change in practice as lecturers became acutely conscious of the pedagogical relationship of each stage of their subject delivery. The thematic analysis demonstrated a behavioural shift from the methods that lecturers employed to ready their subjects for teaching and greater understanding was evident in the rationale for using technology and student engagement mechanisms.

However, it should be noted that the framework is not the solution as there was formative discussion with educational designers and other lecturers about strategies of teaching and experience of using different technologies and this was used in parallel to the framework. The framework has been trialed in one faculty with a small number of participants and the next step in this research study will be to trial the framework in other faculties to determine whether the functions that have been highlighted as appropriate in one faculty are exportable.

\section{References}

[1] Altbach, P. G., Reisberg, L., \& Rumbley, L. E. (2009). Trends in global higher education: Tracking an academic revolution

[2] Boyer, E.L. (1990). Scholarship Reconsidered: Priorities of the Professoriate

[3] Carnegie Foundation for the Advancement of Teaching. Princeton, N.J

[4] Clarke, V., \& Braun, V. (2013). Teaching thematic analysis: Overcoming challenges and developing strategies for effective learning. The psychologist, 26(2), 120-123

[5] Conole, G. (2010) Bridging the gap between policy and practice: A framework for technological intervention. Journal of e-Learning and Knowledge Society, 6(1), 13-27

[6] de Freitas, S. \& Conole, G. (2010) The influence of pervasive and integrative tools on learners' experiences and expectations of study. In R. Sharpe, H. Beetham \& S. de Freitas (Eds), Rethinking learning in the Digital Age, London \& New York: Routledge

[7] Ellis, R.A. and Goodyear, P. (2010) Student experiences of e-learning in higher education: the ecology of sustainable innovation. London: RoutledgeFalmer

[8] Laurillard, D. (2002). Rethinking University Teaching: A Conversational Framework for the Effective Use of Teaching Technologies. 2nd ed. Routledge Falmer: London and New York 
[9] Marks, R. B., Sibley, S. D., \& Arbaugh, J. B. (2005). A structural equation model of predictors for effective online learning. Journal of Management Education, 29(4), 531-563

[10] Salmon, G. (2000). E-moderating: The key to teaching and learning online. United Kingdom: Kogan Page

[11] Seale, J., \& Cooper, M. (2010). E-learning and accessibility: An exploration of the potential role of generic pedagogical tools. Computers \& Education, 54(4), 1107-1116

[12] Smith, D. (2016). Teaching University Subjects Online, Changing Technology and Pedagogical Practice. Advances in Scholarship of Teaching and Learning. 3(1)

[13] Stake, R. E. (1995). The art of case study research. Sage

[14] Steel, C., \& Levy, M. (2009). Creativity and constraint: Understanding teacher beliefs and the use of LMS technologies. Same places, different spaces: Proceedings of ascilite Auckland, 1013-1022 